\title{
Hofbauer Cells: Their Role in Healthy and Complicated Pregnancy
}

\author{
Leticia Reyes ${ }^{1 *}$ and Thaddeus G. Golos ${ }^{2}$ \\ ${ }^{1}$ Department of Pathobiological Sciences, School of Veterinary Medicine, University of Wisconsin-Madison, Madison, WI, \\ United States, ${ }^{2}$ Department of Comparative Biosciences, Wisconsin National Primate Research Center, School of Veterinary \\ Medicine, University of Wisconsin-Madison, Madison, WI, United States
}

Hofbauer cells are placental villous macrophages of fetal origin that are present throughout pregnancy. Although Hofbauer cell populations are antigenically and morphologically heterogeneous, their epigenetic, antigenic, and functional profiles most closely resemble alternatively activated macrophages or what are referred to as $\mathrm{M} 2 \mathrm{a}$, M2b, M2c, and M2d polarity subtypes. Consistent with an M2-like profile, these cells play an important role in placental development including vasculogenesis and angiogenesis. During placental inflammation Hofbauer cells may produce pro-inflammatory cytokines or mediators that damage the villous cell barrier, and induce fibrotic responses within the villi as a continuum of chronic inflammation. However, to date, there is no evidence that Hofbauer cells become classically activated or adopt an M1 polarity phenotype that is able to kill microbes. To the contrary, their predominant M2 like qualities may be why these cells are ineffective in controlling most $\mathrm{TORCH}$ infections. Moreover, Hofbauer cells may contribute to vertical transmission of various pathogens to the fetus since they can harbor live virus and serve as reservoirs within the placenta. The goal of this review is to summarize what is currently known about the role of Hofbauer cells in normal and complicated pregnancies that involve immunologic disorders, inflammation, and/or infection.

Sungkyunkwan Unive

Reviewed by:

Jung-Sun Kim,

South Korea

Éva Pállinger

Semme/weis University, Hungary

*Correspondence:

Leticia Reyes

Ireyes2@wisc.edu

Specialty section:

This article was submitted to Immunological Tolerance and

Regulation,

a section of the journal

Frontiers in Immunology

Received: 28 June 2018

Accepted: 25 October 2018

Published: 15 November 2018

Citation:

Reyes $L$ and Golos TG (2018) Hofbauer Cells: Their Role in Healthy and Complicated Pregnancy.

Front. Immunol. 9:2628

doi: 10.3389/fimmu.2018.02628

\section{HOFBAUER CELLS IN NORMAL PREGNANCY Hofbauer Cell Location and Proposed Function}

Hofbauer cells (HBC) originally referred to round to ovoid placental macrophages with a small nucleus and abundant vacuolated cytoplasm that could be identified by light microscopy (1). Subsequent ultrastructural studies further identified placental macrophages that were spindle or stellate shaped $(2,3)$ and that these cells are of fetal origin (4). HBC is now often used to describe any fetal derived placental macrophage that resides within the placental villous core, amnion, and chorionic lavae (5). HBCs are found in human placental tissue as early as 18 days post-conception (6) and remain throughout gestation (1).

HBCs are presumed to play a role in placental morphogenesis and homeostasis. HBCs are typically in apposition to endothelium and trophoblasts where they can mediate the function of these cells through paracrine signals or possibly cell-to-cell crosstalk (7-9). HBCs are pro-angiogenic in that they express large amounts of vascular endothelial growth factor (VEGF) $(10,11)$, and Sprouty (Spry) proteins Spry 1, 2, and 3 that modulate branching morphogenesis of placental villi (12). It has been suggested that $\mathrm{HBC}$ may participate in vasoregulation of placental blood vessels since they have the capacity to produce prostaglandin $\mathrm{E}_{2}$ and thromboxane in vitro (13). 


\section{Phenotypic Diversity of HBCs}

As is typical of macrophages, HBCs exhibit plasticity and their pleomorphism is likely a reflection of the complex and shifting microenvironment in which they reside (1416). This has been verified through a variety of techniques including electron microscopy, immunohistochemistry, and flow cytometry. Initial descriptions of HBC pleomorphism came from ultrastructural observations that reported 4 types of macrophages based on their shape (3). Histochemical studies have further classified HBC subtypes by their expression of major histocompatibility complex (MHC) type II, complement receptors, lectins, lipopolysaccharide co-receptor (CD14), and CD68 that vary based on HBC location within the placenta as well as gestational stage $(5,15-19)$. Using multi-parameter flow cytometry coupled with serial gating of first trimester macaque HBCs, we previously identified two HBC subsets based on whether or not they expressed CD68 (14). To further illustrate this point we reanalyzed the dataset and added additional samples from late second trimester (gestation day 100), and near term (gestation day 160) (20,21). We specifically measured the expression of HLA-DR, CD14, DC-SIGN, CD68, CD64, and CD163 in HBC by flow cytometry (Figure 1; Table 1, workflow detailed in Supplementary Material). Although our panel was not comprehensive, it included markers previously validated in rhesus macaque HBCs (18), some of which indicate innate immune activation, such as CD14 (23), or immune modulation (DC-SIGN, HLA-DR, CD68) (1, 15, 18, 24). In order to better capture the spectrum of $\mathrm{HBC}$ diversity, we used an unbiased approach to analyze the high-dimensional flow cytometric data. Raw flow cytometry data files were first processed with FlowJo, LLC version 10 software (Ashland, OR). Processed datasets from first $(n=2)$, second $(n=2)$, and third $(n=1)$ trimester pregnancies were then imported into Cytofkit (https://bioconductor.org/packages/cytofkit/), normalized, and analyzed with the DensVM computational clustering tool (22). $t$-Distributed Stochastic Neighbor Embedding ( $t$-SNE) was used to created 2-dimensional maps of all HBC subsets generated by DensVM (Figure 1).

With this approach we identified $10 \mathrm{HBC}$ subsets within macaque placental tissues (Figure 1; Table 1). The $10 \mathrm{HBC}$ subsets were subsequently validated by serial manual gating (Table 2). Both first and third trimester HBC populations were more diverse than the second trimester ( 8 vs. 5 clusters, respectively). This is not unusual given the physiological events that occur during these stages of pregnancy. For example, during the first trimester, HBCs are thought to participate in placental villous growth and tissue remodeling (13). At the same time HBCs in the vicinity of the placental bed may be affected by the inflammatory processes necessary for decidualization and embryo implantation (25). During the latter part of the third trimester, HBCs scattered through the placenta are exposed to various products released from senescent trophoblasts (26), necrotic cell debris associated with fibrinoid deposits within aging placental villi (13), and inflammatory mediators produced during parturition (27). These may promote the development of specialized subsets of HBCs in response to their microenvironment. Alternatively, they may represent different populations of fetal monocytes that are trafficking to the placenta across gestation.

In order to assess gestation dependent changes in $\mathrm{HBC}$ subsets, marker expression heatmaps specific to each gestational stage were generated (Figure 2). We found that both CD163 and CD64 appeared to be constitutively expressed in all HBC subsets throughout pregnancy, indicating that these markers may be well-suited for the identification of HBCs in general. However, CD68 which is often used as a single marker to identify $\mathrm{HBCs}$ had variable expression over time. Namely, the intensity of CD68 expression peaked in the second trimester and significantly dropped as pregnancy progressed. This temporal expression pattern is similar to previous studies that described human HBC populations as changing in density as pregnancy progressed $(1,24)$.

As expected (5), there was at least one population of HBC that was negative for HLA-DR (cluster 5). Of the HBC subsets that were positive, HLA-DR expression followed a similar pattern to CD68 in that peak expression was observed in second trimester placenta. However, contrary to human studies (5), we found the proportion of HLA-DR positive cells in first trimester placenta to be greater than third trimester tissue. This may be due to timing of sampling since human studies evaluated tissues collected during 8-10 weeks gestation (5) whereas we examined tissues collected at a later gestational time point that developmentally would be equivalent to 17-18 weeks in human gestation.

DC-SIGN positive HBCs were present in all 3 stages of pregnancy; albeit with varying degrees of DC-SIGN expression. Consistent with Yang et al. (28) we found that DC-SIGN positive third trimester macaque HBCs co-expressed CD14, CD68, and CD163. In contrast to Bockle et al (29), we detected a large population of DC-SIGN positive HBC in third trimester placenta that co-expressed HLA-DR (23\% in cluster 6). One caveat is that these cells had dim expression of both markers, which may explain why these cells may not be readily detected by immunofluorescent histology.

Of all the markers that we studied, the proportion of CD14 positive cells and their level of CD14 expression was the most diverse. Midgestation placenta, which is characterized by immune tolerance, had the greatest proportion of $\mathrm{CD} 14^{\mathrm{Hi}}$ positive $\mathrm{HBCs}$ that were also $\mathrm{CD} 163^{\mathrm{Hi}}$ (cluster 10). Although increased CD14 expression has been linked to pro-inflammatory HBCs (23), in normal pregnancy CD14 expression may represent an immune suppressed phenotype. $\mathrm{CD} 14^{\mathrm{Hi}} / \mathrm{CD} 163^{\mathrm{Hi}}$ expression as seen in cluster 10, is characteristic of immunosuppressive M2d or tumor associated macrophages (TAM) (30). CD14 positive HBCs also express anti-inflammatory TGF- $\beta$ and IL-10 (31).

Even though this was a pilot experiment with a small sample size, our results demonstrate the potential of utilizing computational methods to analyze multidimensional data from HBCs. For instance, we obtained a global perspective on how $\mathrm{HBC}$ subsets change during pregnancy. Moreover, we gained insights into which macrophage markers may or may not be suitable for the general identification of HBCs by flow cytometric or immunohistochemical approaches. 
A

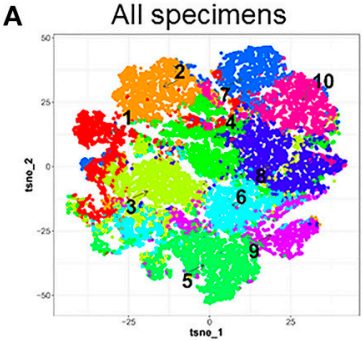

GD 100 only

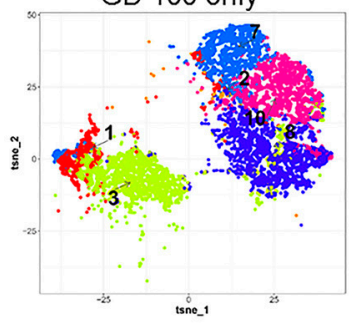

DensVM

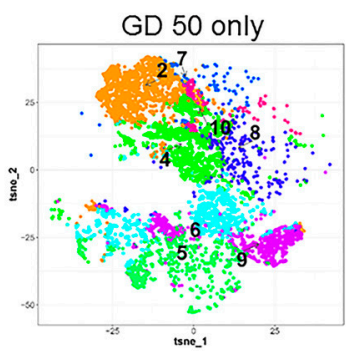

Term only

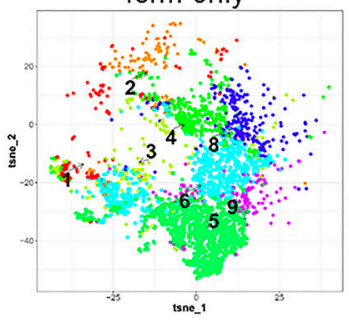

stoe-1

FIGURE 1 | Marker defined HBC subsets within macaque placenta collected at different stages of gestation: Gestation day (GD) $50 \pm 2$ days $(n=2)$, GD100 \pm 2 days $(n=2)$, and Term. (A) $t$-SNE visualization of DensVM generated HBC clusters of combined flow cytometry data from all gestation stages (All specimens) and by each individual gestation stage. (B) Marker and cluster specific DensVM median heatmap generated with flow cytometry data from all gestation stages. Clustering was ranked by both HBC cluster group (designated by row) and marker median expression (column). Images were created with Cytofkit ShinyAPP (22).

TABLE 1 | Marker profiles of HBC subsets generated with DensVM clustering algorithm (22).

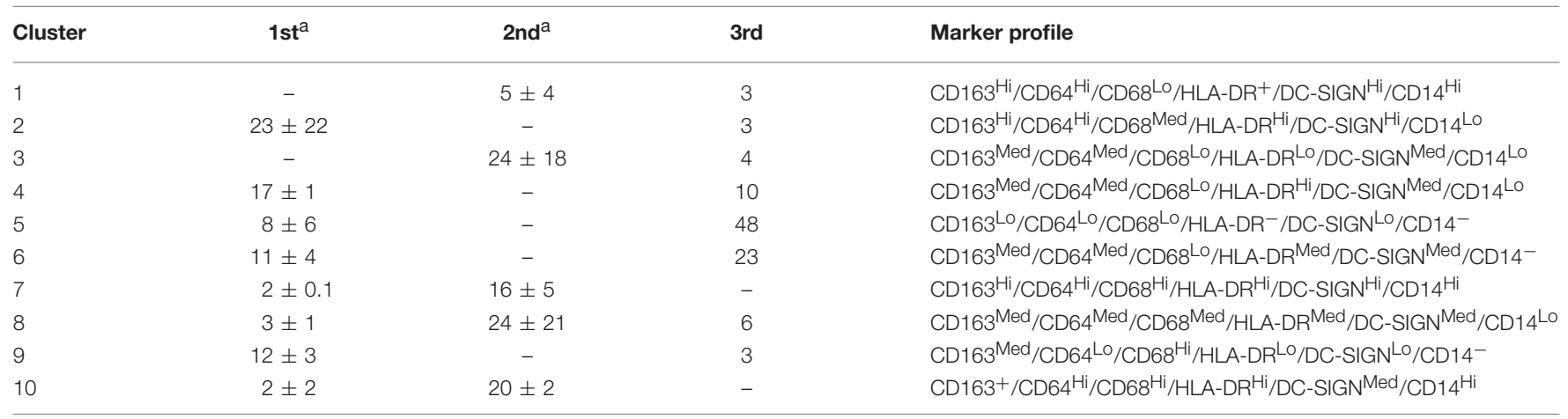

${ }^{a}$ Values represent the mean $\pm S D \%$ positive cells per group $(n=2)$ per gestation group.

TABLE 2 | Marker profiles of HBC subsets generated by manual gating using FlowJo Software.

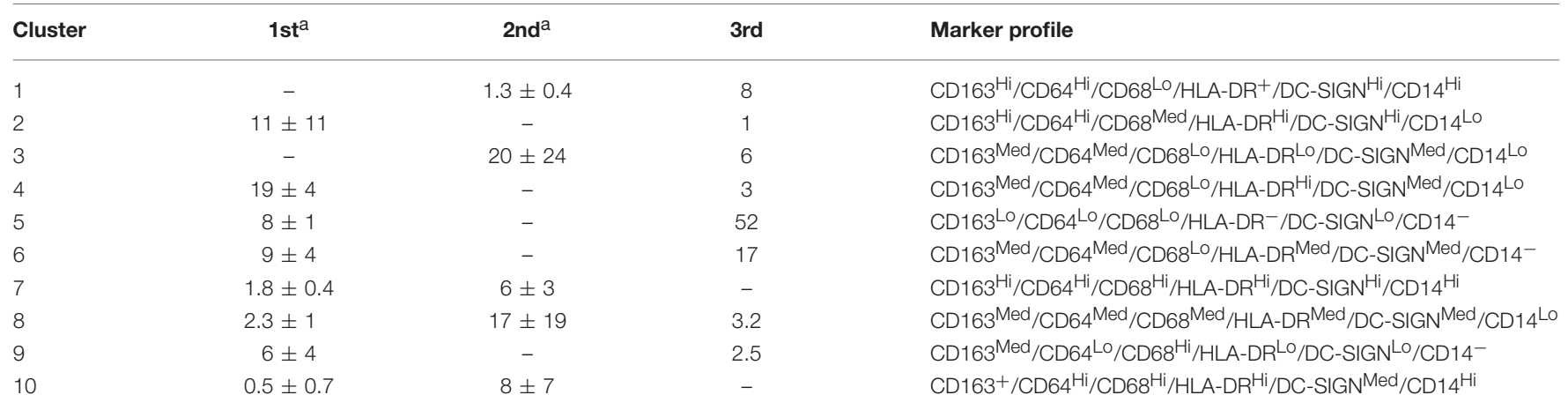

a Values represent the mean $\pm S D \%$ positive cells per group $(n=2)$ per gestation group. 
TABLE 3 | General features of macrophage polarity pertinent to $\operatorname{HBC}(30,33,34)$.

\begin{tabular}{|c|c|c|c|c|c|}
\hline & M1 & M2a & M2b & M2c & M2d \\
\hline Stimulus & $\begin{array}{l}\mathrm{IFN}-\gamma+\mathrm{LPS} \\
\mathrm{IFN}-\gamma+\mathrm{TNF} \\
\mathrm{GM}-\mathrm{CSF}\end{array}$ & $\begin{array}{l}\text { IL-4 } \\
\text { IL-13 } \\
\text { Fungal and parasitic } \\
\text { infections }\end{array}$ & $\begin{array}{l}\text { Immune complexes } \\
\text { IL-1R }\end{array}$ & $\begin{array}{l}\text { IL-10 } \\
\text { TGF- } \beta \\
\text { Glucocorticoids }\end{array}$ & $\begin{array}{l}\text { IL-6 } \\
\text { LIF } \\
\text { M-CSF } \\
\text { Adenosine }\end{array}$ \\
\hline Surface markers & $\begin{array}{l}\mathrm{CD} 80 \\
\mathrm{MHC} \|\end{array}$ & $\begin{array}{l}\text { CD163 } \\
\text { IL-1R } \\
\text { MHC \| } \\
\text { CD206 } \\
\text { IL-RN } \\
\text { DC-SIGN }\end{array}$ & $\begin{array}{l}\text { CD86 } \\
\text { MHC ॥ }\end{array}$ & $\begin{array}{l}\text { CD163 } \\
\text { TLR1 } \\
\text { TLR8 } \\
\text { CD206 } \\
\text { CD14 }\end{array}$ & $\begin{array}{l}\text { CD163 } \\
\text { CD14 } \\
\text { CD85 }\end{array}$ \\
\hline Secreted factors & $\begin{array}{l}\text { TNF } \\
\text { IL-1 } 13 \\
\text { IL-6 } \\
\text { IL-12 } \\
\text { IL-23 } \\
\text { CCL10 } \\
\text { CCL11 } \\
\text { CCL5 } \\
\text { CCL8 } \\
\text { CCL9 } \\
\text { CCL2 } \\
\text { CCL3 } \\
\text { CCL4 }\end{array}$ & $\begin{array}{l}\text { IL-10 } \\
\text { TGF- } \beta \\
\text { IL-1ra }\end{array}$ & $\begin{array}{l}\text { IL-1 } \\
\text { IL-6 } \\
\text { IL-10 } \\
\text { TNF- } \alpha \\
\text { CCL1 }\end{array}$ & $\begin{array}{l}\text { IL-10 } \\
\text { TGF- } \beta \\
\text { CCR2 } \\
\text { Pentraxin } 3\end{array}$ & $\begin{array}{l}\text { VEGF } \\
\text { MMP-9 } \\
\text { IDO } \\
\text { IL-10 } \\
\text { IL-12 } \\
\text { TNF- } \alpha \\
\text { TGF- } \beta \\
\text { CCL5 } \\
\text { CXCL10 } \\
\text { CXCL16 }\end{array}$ \\
\hline Biological effects & $\begin{array}{l}\text { TH1 responses } \\
\text { Killing intracellular } \\
\text { pathogens } \\
\text { Tumor resistance }\end{array}$ & $\begin{array}{l}\text { TH2 responses } \\
\text { Killing of extracellular } \\
\text { responses }\end{array}$ & $\begin{array}{l}\text { TH2 activation } \\
\text { Immune regulation }\end{array}$ & $\begin{array}{l}\text { Immune regulation } \\
\text { Matrix deposition and } \\
\text { tissue remodeling }\end{array}$ & $\begin{array}{l}\text { Immune suppression } \\
\text { Angiogenesis }\end{array}$ \\
\hline
\end{tabular}

\section{Functional Diversity of HBCs}

Mills et al. (32) were the first to introduce the concept that macrophage function could be polarized based on how the cell metabolized arginine. Arginine conversion to nitric oxide was linked to a macrophage that produced IFN- $\gamma$ and inhibited wound healing, which was labeled as M1. Arginine conversion to ornithine was linked to a macrophage that produced TGF$\beta$ and promoted wound healing, this phenotype was labeled as M2. Over the years, the criteria for defining a macrophage as M1 has expanded (Table 2) to include microbicidal activity, and the production of pro-inflammatory cytokines and chemokines that promote cell mediated (TH1 type) responses. M2 polarity phenotype has been divided subsequently into M2a, M2b, M2c, and M2d subcategories (reviewed by Martinez et al. (33)), which are based on their responses to various agonists (Table 3). Collectively, M2 subtypes are linked by a dominant $\mathrm{TH} 2$ response profile, their development in response to fungal or helminth infections, and their role in tissue remodeling. However, M2b polarized macrophages share some qualities in M1 in that they can be pro-inflammatory by producing TNF, IL-1, and IL-6 along with IL-10, but they lack microbicidal activity.

Since HBC are macrophages, it has been assumed that these cells protect the placenta and fetus from infection (13), which would be consistent with an M1 phenotype. However, there is no experimental evidence that HBCs within the placenta are capable of killing microbes (discussed in the next section of this review). Pro-M1 genes in HBC, such as TLR9, IL1B, IL12RB2, CD48, and FGR are silenced by methylation (35). On the other hand, pro-M2 genes, such as CCL2, CCL13, CCL14, CD209, and $\mathrm{A} 2 \mathrm{M}$ are hypomethylated in $\mathrm{HBCs}$ and thus available for transcription (35). Collectively, HBCs isolated from term human placenta display M2a, M2b, and M2c characteristics based on cell surface marker profiles and cytokine expression $(19,31,36)$. HBCs also share some features with M2d phenotype in that they are immune suppressive, pro-angiogenic, and co-express CD163 and CD14 (7, 10, 12, 36). Moreover, HBCs form multinucleated giant cells that express matrix metalloproteinase genes along with VEGF-C (37), which are also features of M2d. Hypothetically, a normal pregnancy has a balanced blend of HBC subtypes that functionally complement each other in providing optimal vascular development, villous growth and immune tolerance. Conversely, an imbalance in HBC subtypes may bring about or exacerbate pathologic pregnancy.

\section{THE ROLE OF HBCS IN PREGNANCY COMPLICATIONS}

\section{Villitis}

Villitis is a histopathologic diagnosis with multiple underlying etiologies (38). It can be a consequence of hematogenous infection of the placenta by TORCH organisms that include 


\section{A}

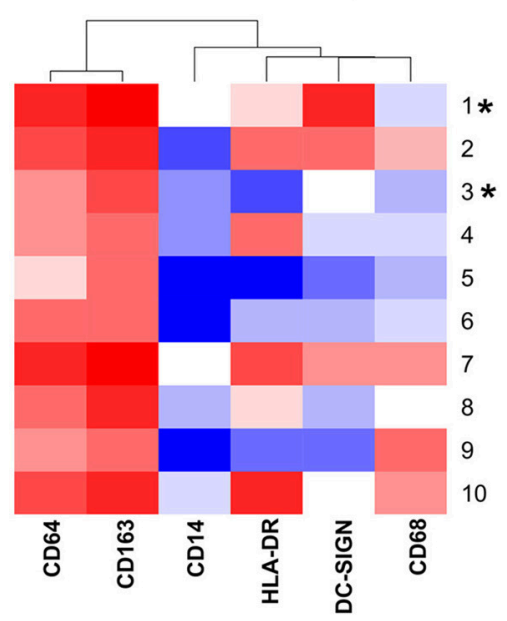

B DensVM median Heat Map

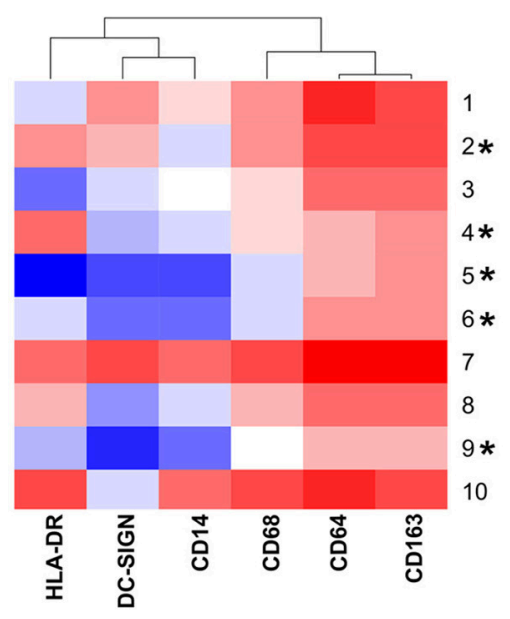

C DensVM median Heat Map

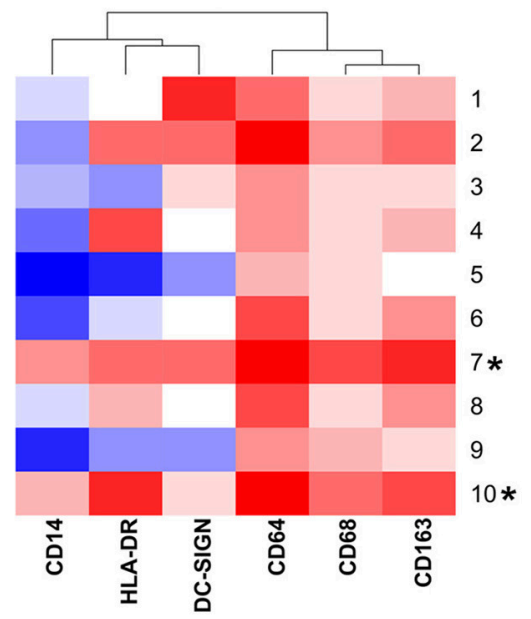

FIGURE 2 | DensVM median heatmaps specific to each gestation stage. (A) GD50 \pm 2 days, (B) GD100 \pm 2 days $(n=2)$, and (C) Term $(n=1)$. Heatmaps were clustered by median expression of each marker (column). *Denotes HBC clusters that contained $1 \%$ of cells for that specific gestation stage. Images were created with Cytofkit ShinyAPP (22).
Toxoplasma, Others (syphilis, varicella-zoster, parvovirus B19), Rubella, Cytomegalovirus (CMV), and Herpes infections $(38,39)$. However, most cases of villitis are not associated with infection, but may be immune mediated $(40,41)$. Acute villitis is usually caused by infection and it characterized by polymorphonuclear leukocytic infiltration of the villi with or without necrosis. Listeria monocytogenes infection during pregnancy is one of the most common causes of acute villitis $(13,42)$. Placental infection with Treponema pallidin (syphilis) may also present as acute villitis, but chronic villitis is more characteristic of congenital syphilis $(43,44)$. On the other hand chronic villitis is characterized by infiltration of the tissue by lymphocytes and macrophages. It may be accompanied by cellular proliferation and fibrosis of the villi. Most cases of villitis are multifocal and asymptomatic, but the lesion can be more extensive leading to preterm birth or miscarriage.

Perturbed $\mathrm{HBC}$ function is a common occurrence in chronic villitis. HBC hyperplasia or proliferation is seen in chronic villitis caused by infection with CMV, Zika, Herpes virus, Coxsackie, and villitis of unknown etiology (VUE) (38, 45-47). Regardless of the underlying cause, HBCs in chronic villitis exhibit an inflammatory phenotype. Satosar and colleagues showed an increase in the number of TNF positive HBCs with a concomitant decrease in SOCS-1 (suppressors of cytokine signaling) positive HBCs in villitis placentas positive for viral and bacterial infection (45). A similar response is also evident in VUE, which is now recognized to be an immune mediated process that resembles maternal anti-fetal rejection and placental graft vs. host disease (40). In VUE, hyperplastic HBCs are intermixed with infiltrating maternal macrophages and $\mathrm{CD} 8^{+} \mathrm{T}$ cells with an inflammatory transcriptome that is similar to the biological processes that occur during antigen presentation and immune response (40). In particular, HBCs in VUE are positive for CXCL9, CXCL10, CXCL11, and CXCL13 $(40,45)$. In this scenario HBCs are thought to be contributing to placental damage. In the case of TORCH infections, it is unknown whether HBCs are contributing to placental damage, or controlling infection. The presence of viral inclusions (CMV, Herpes Simplex, Coxsackie) or parasites (Toxoplasma and Leishmania) can certainly be found in HBCs, but it is unknown if these organisms are live and replication, or dying within the cell. HBCs are harboring live organisms these organisms are viable in these cells $(38,39)$.

HBC hyperplasia without villitis has also been observed with placental Zika virus infection $(48,49)$. This lesion is characterized by enlarged, hydropic chorionic villi, hyperplasia and focal proliferation of $\mathrm{HBC}$, without necrosis or lymphocytic infiltration of the affected villi $(48,49)$. Some of the proliferating HBCs were found to contain Zika virus (49). Since Zika has been shown to replicate in HBCs (50-52), it has been proposed by several investigators that these cells may serve as a source of infection to the fetus $(48,53)$. However, the significance of HBCs in releasing infectious Zika virions is questionable since by Gavegnano and colleagues showed that Zika virions released from HBCs were incapable of infecting susceptible Vero cells (54). Whether antiviral responses in HBC are effective or compromised in vivo is yet to be determined. Regardless, perturbations in $\mathrm{HBCs}$ during placental infection with Zika 
suggest that these cells have altered function that may be detrimental to placental morphogenesis.

\section{Preterm Delivery}

There are a limited number of studies concerning HBCs in preterm delivery. These have been limited to chorioamnionitisinduced spontaneous preterm birth, severe preeclampsia, and HELLP syndrome. Two independent studies have shown that the density of $\mathrm{CD}^{+} 8^{+} \mathrm{HBCs}$ are significantly reduced in chorioamnionitis $(24,37)$. The underlying mechanism for a decrease in HBCs during chorioamnionitis is unknown but it has been speculated that these cells may be undergoing apoptosis (37). HBC function, particularly multinucleated giant cells, is altered in placentas with chorioamnionitis. Namely, these cells exhibited decreased tolerogenic activity compared to the same cells retrieved from normal pregnancies (37). The application of high dimensional flow cytometry may allow discernment of the significance of a decrease in the density of $\mathrm{CD}^{+} 8^{+}$cells: is CD68 selectively lost from a subset of cells? Does a different population of HBCs arise in these placentas?

Although a subset of preeclampsia patients develop HELLP, HELLP is considered a separate syndrome. Preeclampsia and HELLP have different clinical presentations $(55,56)$. Classical preeclampsia is characterized by hypertension and proteinuria, whereas HELLP involves activation of the coagulation system (55). Pathologic features within the placenta also differ between preeclampsia and HELLP. Infarction, intervillous thrombosis, and abruption is more common in placentas from preeclampsia patients than patients with HELLP (55). Furthermore, HBC numbers, and their expression of DC-SIGN and IL-10 are significantly reduced in patients with severe preeclampsia (28, 57). It has been suggested that the reduction of HBCs in preeclampsia may be promoting inflammatory damage due to the loss of tolerance-promoting HBCs (28). In contrast to preeclampsia, patients with HELLP exhibit increased numbers of $\mathrm{CD} 8^{+} \mathrm{HBCs}$, and it was concluded that this may be due to increased inflammation or an adaptive response (56).

\section{CONCLUDING REMARKS}

Our understanding of the role of HBCs in pregnancy is still rudimentary, but current evidence provides a compelling

\section{REFERENCES}

1. Ingman K, Cookson VJKW, Jones CJP, Aplin JD. Characterisation of Hofbauer cells in first and second trimester placenta: incidence, phenotype, survival in vitro and motility. Placenta (2010) 31:535-44. doi: $10.1016 /$ j.placenta.2010.03.003

2. Castellucci M, Schweikhart G, Kaufmann P, Zaccheo D. The stromal architecture of the immature intermediate villus of the human placenta. Functional and clinical implications. Gynecol Obstet Invest. (1984) 18:95-99.

3. Castellucci M, Zaccheo D, Pescetto G. A three-dimensional study of the normal human placental villous core. I. The Hofbauer cells. Cell Tissue Res. (1980) 210:235-47.

4. Kim JS, Romero R, Kim MR, Kim YM, Friel L, Espinoza J, et al. Involvement of Hofbauer cells and maternal $\mathrm{T}$ cells in villitis of unknown aetiology. Histopathology (2008) 52:457-64. doi: 10.1111/j.1365-2559.2008.02964.x argument that these cells are important in placental development and homeostasis. At least in some pregnancy complications, such as VUE and chorioamnionitis, HBC dysfunction may be contributing to disease pathogenesis. Since HBCs exhibit functional plasticity, they may be ideal targets for therapeutic manipulation during disease states. However, additional studies are needed to better define the functional role of various $\mathrm{HBC}$ subsets in both health and disease.

\section{ETHICS STATEMENT}

Macaque data presented in this article was obtained with approval from the University of Wisconsin Institutional Animal Care and Use Committee.

\section{AUTHOR CONTRIBUTIONS}

LR conceived of the topic, conducted the research, and wrote the manuscript. TG assisted with non-human primate studies, and contributed to the writing of the manuscript.

\section{FUNDING}

This work was supported by award number R21AI136014-01. The content is solely the responsibility of the authors and does not necessarily represent the official views of the National Institutes of Health.

\section{ACKNOWLEDGMENTS}

The authors thank Aleks Stanic-Kostic and Bryce Wolfe for advice and assistance in implementing high-dimensional flow cytometry, and Xiao-jun $\mathrm{Wu}$ for assistance in Hofbauer cell isolation.

\section{SUPPLEMENTARY MATERIAL}

The Supplementary Material for this article can be found online at: https://www.frontiersin.org/articles/10.3389/fimmu. 2018.02628/full\#supplementary-material

5. Bulmer JN, Johnson PM. Macrophage populations in the human placenta and amniochorion. Clin Exp Immunol. (1984) 57:393-403.

6. Kurt B. The human placenta. J. D. Boyd and W. J. Hamilton. Heffer, Cambridge, 365 pp. 1970. Teratology (1973) 8:77-8. doi: 10.1002/tera.1420080118

7. Cervar M, Blaschitz A, Dohr G, Desoye G. Paracrine regulation of distinct trophoblast functions in vitro by placental macrophages. Cell Tissue Res. (1999) 295:297-305.

8. Seval Y, Korgun ET, Demir R. Hofbauer cells in early human placenta: possible implications in vasculogenesis and angiogenesis. Placenta (2007) 28:841-5. doi: 10.1016/j.placenta.2007.01.010

9. Khan S, Katabuchi H, Araki M, Nishimura R, Okamura H. Human villous macrophage-conditioned media enhance human trophoblast growth and differentiation in vitro. Biol Reprod. (2000) 62:1075-83. doi: 10.1095/biolreprod62.4.1075 
10. Demir R, Kayisli UA, Seval Y, Celik-Ozenci C, Korgun ET, Demir-Weusten AY, et al. Sequential expression of VEGF and its receptors in human placental villi during very early pregnancy: differences between placental vasculogenesis and angiogenesis. Placenta (2004) 25:560-72. doi: 10.1016/j.placenta.2003.11.011

11. Ahmed A, Li XF, Dunk C, Whittle MJ, Rushton DI, Rollason T. Colocalisation of vascular endothelial growth factor and its Flt-1 receptor in human placenta. Growth Factors (1995) 12:235-43.

12. Anteby EY, Natanson-Yaron S, Greenfield C, Goldman-Wohl D, HaimovKochman R, Holzer H, et al. Human placental Hofbauer cells express sprouty proteins: a possible modulating mechanism of villous branching. Placenta (2005) 26:476-83. doi: 10.1016/j.placenta.2004.08.008

13. Benirschke K, Burton, Graham J, Baergen, Rebecca N. Pathology of the Human Placenta Berlin Heidelberg: Springer-Verlag Berlin Heidelberg (2012). 941 p.

14. Reyes L, Wolfe B, Golos T. Hofbauer cells: placental macrophages of fetal origin. Results Probl Cell Differ. (2017) 62:45-60. doi: 10.1007/978-3-319-54090-0_3

15. Goldstein J, Braverman M, Salafia C, Buckley P. The phenotype of human placental macrophages and its variation with gestational age. Am J Pathol. (1988) 133:648-59.

16. Bulmer JN, Morrison L, Smith JC. Expression of class II MHC gene products by macrophages in human uteroplacental tissue. Immunology (1988) 63:707-14.

17. Sutton L, Mason DY, Redman CW. HLA-DR positive cells in the human placenta. Immunology (1983) 49:103-12.

18. Breburda EE, Dambaeva SV, Slukvin, II, Golos TG. Selective distribution and pregnancy-specific expression of DC-SIGN at the maternal-fetal interface in the rhesus macaque: DC-SIGN is a putative marker of the recognition of pregnancy. Placenta (2006) 27:11-21. doi: 10.1016/j.placenta.2004.11.006

19. Schliefsteiner C, Peinhaupt M, Kopp S, Logl J, Lang-Olip I, Hiden U, et al. Human placental Hofbauer cells maintain an anti-inflammatory M2 phenotype despite the presence of gestational diabetes mellitus. Front Immunol. (2017) 8:888. doi: 10.3389/fimmu.2017.00888

20. de Rijk EPCT, Van Esch E. The macaque placenta-a mini-review. Toxicol Pathol. (2008) 36(7_Suppl.):108S-18S. doi: 10.1177/01926233083 26095

21. Patrick LW. The fine structure of the placental villi of the rhesus monkey (Macaca mulatta). Anat Rec. (1970) 167:141-63. doi: 10.1002/ar.1091670203

22. Chen H, Lau MC, Wong MT, Newell EW, Poidinger M, Chen J. Cytofkit: a bioconductor package for an integrated mass cytometry data analysis pipeline. PLOS Comput Biol. (2016) 12:e1005112. doi: 10.1371/journal.pcbi.1005112

23. Young OM, Tang Z, Niven-Fairchild T, Tadesse S, Krikun G, Norwitz ER, et al. Toll-like receptor-mediated responses by placental Hofbauer cells (HBCs): a potential pro-inflammatory role for fetal M2 macrophages. Am J Reprod Immunol. (2015) 73:22-35. doi: 10.1111/aji.12336

24. Vinnars MT, Rindsjo E, Ghazi S, Sundberg A, Papadogiannakis N. The number of CD68(+) (Hofbauer) cells is decreased in placentas with chorioamnionitis and with advancing gestational age. Pediatr Dev Pathol. (2010) 13:300-4. doi: 10.2350/09-03-0632-OA.1

25. Dekel N, Gnainsky Y, Granot I, Racicot K, Mor G. The role of inflammation for a successful implantation. Am J Reprod Immunol. (2014) 72:141-7. doi: 10.1111/aji.12266

26. Sultana Z, Maiti K, Dedman L, Smith R. Is there a role for placental senescence in the genesis of obstetric complications and fetal growth restriction? Am J Obstet Gynecol. (2018) 218(2 Supplement):S762-73. doi: 10.1016/j.ajog.2017.11.567

27. Romero R, Espinoza J, Goncalves LF, Kusanovic JP, Friel LA, Nien JK. Inflammation in preterm and term labour and delivery. Semin Fetal Neonatal Med. (2006) 11:317-26. doi: 10.1016/j.siny.2006.05.001

28. Yang SW, Cho EH, Choi SY, Lee YK, Park JH, Kim MK, et al. DC-SIGN expression in Hofbauer cells may play an important role in immune tolerance in fetal chorionic villi during the development of preeclampsia. J Reprod Immunol. (2017) 124:30-7. doi: 10.1016/j.jri.2017.09.012

29. Bockle BC, Solder E, Kind S, Romani N, Sepp NT. DC-sign+ CD163 ${ }^{+}$ macrophages expressing hyaluronan receptor LYVE-1 are located within chorion villi of the placenta. Placenta (2008) 29:187-92. doi: $10.1016 /$ j.placenta.2007.11.003

30. Duluc D, Delneste Y, Tan F, Moles MP, Grimaud L, Lenoir J, et al. Tumorassociated leukemia inhibitory factor and IL- 6 skew monocyte differentiation into tumor-associated macrophage-like cells. Blood (2007) 110:4319-30. doi: 10.1182/blood-2007-02-072587

31. Johnson EL, Chakraborty R. Placental Hofbauer cells limit HIV-1 replication and potentially offset mother to child transmission (MTCT) by induction of immunoregulatory cytokines. Retrovirology (2012) 9:101. doi: 10.1186/1742-4690-9-101

32. Mills CD, Kincaid K, Alt JM, Heilman MJ, Hill AM. M-1/M-2 Macrophages and the Th1/Th2 Paradigm. J Immunol. (2000) 164:6166-73. doi: 10.4049/jimmunol.164.12.6166

33. Martinez FO, Sica A, Mantovani A, Locati M. Macrophage activation and polarization. Front Biosci. (2008) 13:2692. doi: 10.2741/2692

34. Roszer T. Understanding the mysterious M2 macrophage through activation markers and effector mechanisms. Mediators Inflamm. (2015) 2015:816460. doi: 10.1155/2015/816460

35. Kim SY, Romero R, Tarca AL, Bhatti G, Kim CJ, Lee J, et al. Methylome of fetal and maternal monocytes and macrophages at the feto-maternal interface. Am J Reprod Immunol. (2012) 68:8-27. doi: 10.1111/j.1600-0897.2012.01108.x

36. Loegl J, Hiden U, Nussbaumer E, Schliefsteiner C, Cvitic S, Lang I, et al. Hofbauer cells of M2a, M2b and M2c polarization may regulate feto-placental angiogenesis. Reproduction (2016) 152:447-55. doi: 10.1530/rep-16-0159

37. Ben Amara A, Gorvel L, Baulan K, Derain-Court J, Buffat C, Verollet $\mathrm{C}$, et al. Placental macrophages are impaired in chorioamnionitis, an infectious pathology of the placenta. J Immunol. (2013) 191:5501-14. doi: 10.4049/jimmunol.1300988

38. Bittencourt AL, Garcia AG. The placenta in hematogenous infections. Pediatr Pathol Mol Med. (2002) 21:401-32. doi: 10.1080/152279502760157768

39. Faye-Petersen OM. The placenta in preterm birth. J Clin Pathol. (2008) 61:1261-75. doi: 10.1136/jcp.2008.055244

40. Kim MJ, Romero R, Kim CJ, Tarca AL, Chhauy S, LaJeunesse C, et al. Villitis of unknown etiology is associated with a distinct pattern of chemokine upregulation in the feto-maternal and placental compartments: implications for conjoint maternal allograft rejection and maternal anti-fetal graft-versus-host disease. J Immunol. (2009) 182:3919-27. doi: 10.4049/jimmunol.0803834

41. Tamblyn JA, Lissauer DM, Powell R, Cox P, Kilby MD. The immunological basis of villitis of unknown etiology-review. Placenta (2013) 34:846-55. doi: 10.1016/j.placenta.2013.07.002

42. Wolfe B, Wiepz GJ, Schotzko M, Bondarenko GI, Durning M, Simmons $\mathrm{HA}$, et al. Acute fetal demise with first trimester maternal infection resulting from listeria monocytogenes in a nonhuman primate model. mBio (2017) 8:e01938-16. doi: 10.1128/mBio.01938-16

43. Qureshi F, Jacques SM, Reyes MP. Placental histopathology in syphilis. Hum Pathol. (1993) 24:779-84.

44. Genest DR, Choi-Hong SR, Tate JE, Qureshi F, Jacques SM, Crum C. Diagnosis of congenital syphilis from placental examination: comparison of histopathology, Steiner stain, and polymerase chain reaction for Treponema pallidum DNA. Hum Pathol. (1996) 27:366-72.

45. Satosar A, Ramirez NC, Bartholomew D, Davis J, Nuovo GJ. Histologic correlates of viral and bacterial infection of the placenta associated with severe morbidity and mortality in the newborn. Hum Pathol. (2004) 35:536-45. doi: 10.1016/j.humpath.2004.01.015

46. Schwartz DA, Khan R, Stoll B. Characterization of the fetal inflammatory response to cytomegalovirus placentitis. An immunohistochemical study. Arch Pathol Lab Med. (1992) 116:21-7.

47. Noronha L, Zanluca C, Azevedo ML, Luz KG, Santos CN. Zika virus damages the human placental barrier and presents marked fetal neurotropism. Mem Inst Oswaldo Cruz (2016) 111:287-93. doi: 10.1590/0074-02760 160085

48. Schwartz DA. Viral infection, proliferation, and hyperplasia of Hofbauer cells and absence of inflammation characterize the placental pathology of fetuses with congenital Zika virus infection. Arch Gynecol Obstet. (2017) 295:1361-8. doi: 10.1007/s00404-017-4361-5

49. Rosenberg AZ, Yu W, Hill DA, Reyes CA, Schwartz DA. Placental pathology of Zika virus: viral infection of the placenta induces villous stromal macrophage (Hofbauer cell) proliferation and hyperplasia. Arch Pathol Lab Med. (2017) 141:43-8. doi: 10.5858/arpa.2016-0401-OA

50. Jurado KA, Simoni MK, Tang Z, Uraki R, Hwang J, Householder S, et al. Zika virus productively infects primary human placenta-specific macrophages. JCI Insight (2016) 1:88461. doi: 10.1172/jci.insight.88461 
51. Quicke KM, Bowen JR, Johnson EL, McDonald CE, Ma H, O’Neal JT, et al. Zika virus infects human placental macrophages. Cell Host Microbe (2016) 20:83-90. doi: 10.1016/j.chom.2016. 05.015

52. Tabata T, Petitt M, Puerta-Guardo H, Michlmayr D, Wang C, Fang-Hoover J, et al. Zika virus targets different primary human placental cells, suggesting two routes for vertical transmission. Cell Host Microbe (2016) 20:155-66. doi: 10.1016/j.chom.2016.07.002

53. Simoni MK, Jurado KA, Abrahams VM, Fikrig E, Guller S. Zika virus infection of Hofbauer cells. Am J Reprod Immunol. (2016) 77:e12613. doi: 10.1111/aji.12613

54. Gavegnano C, Bassit LC, Cox BD, Hsiao HM, Johnson EL, Suthar M, et al. Jak inhibitors modulate production of replication-competent Zika virus in human Hofbauer, trophoblasts, and neuroblastoma cells. Pathog Immun. (2017) 2:199-218. doi: 10.20411/pai.v2i2.190

55. Vinnars MT, Wijnaendts LC, Westgren M, Bolte AC, Papadogiannakis $\mathrm{N}$, Nasiell J. Severe preeclampsia with and without HELLP differ with regard to placental pathology. Hypertension (2008) 51:1295-9. doi: 10.1161/HYPERTENSIONAHA.107. 104844
56. Evsen MS, Kalkanli S, Deveci E, Sak ME, Ozler A, Baran O, et al. Human placental macrophages (Hofbauer cells) in severe preeclampsia complicated by HELLP syndrome:v immunohistochemistry of chorionic villi. Anal Quant Cytopathol Histpathol. (2013) 35:283-8.

57. Tang Z, Buhimschi IA, Buhimschi CS, Tadesse S, Norwitz E, Niven-Fairchild $\mathrm{T}$, et al. Decreased levels of folate receptor-beta and reduced numbers of fetal macrophages (Hofbauer cells) in placentas from pregnancies with severe preeclampsia. Am J Reprod Immunol. (2013) 70:104-15. doi: 10.1111/aji.12112

Conflict of Interest Statement: The authors declare that the research was conducted in the absence of any commercial or financial relationships that could be construed as a potential conflict of interest.

Copyright (c) 2018 Reyes and Golos. This is an open-access article distributed under the terms of the Creative Commons Attribution License (CC BY). The use, distribution or reproduction in other forums is permitted, provided the original author(s) and the copyright owner(s) are credited and that the original publication in this journal is cited, in accordance with accepted academic practice. No use, distribution or reproduction is permitted which does not comply with these terms. 